Article

\title{
The Percentage of Free PSA and Urinary Markers Distinguish Prostate Cancer from Benign Hyperplasia and Contribute to a More Accurate Indication for Prostate Biopsy
}

\author{
Zlata Huskova ${ }^{1}{ }^{1}$, Jana Knillova ${ }^{1}$, Zdenek Kolar ${ }^{1}$, Jana Vrbkova ${ }^{2}$, Milan Kral ${ }^{3, *}$ \\ and Jan Bouchal ${ }^{1, *(D)}$ \\ 1 Department of Clinical and Molecular Pathology, Faculty of Medicine and Dentistry, \\ Palacky University and University Hospital, 77900 Olomouc, Czech Republic; zlata.huskova@upol.cz (Z.H.); \\ jana.knillova@upol.cz (J.K.); zdenek.kolar@upol.cz (Z.K.) \\ 2 Institute of Molecular and Translational Medicine, Faculty of Medicine and Dentistry, Palacky University, \\ 77900 Olomouc, Czech Republic; jana.vrbkova@upol.cz \\ 3 Department of Urology, University Hospital, 77900 Olomouc, Czech Republic \\ * Correspondence: kral.milan@seznam.cz (M.K.); jan.bouchal@upol.cz (J.B.)
}

Received: 28 April 2020; Accepted: 23 June 2020; Published: 25 June 2020

\begin{abstract}
The main advantage of urinary biomarkers is their noninvasive character and the ability to detect multifocal prostate cancer $(\mathrm{CaP})$. We have previously implemented a quadruplex assay of urinary markers into clinical practice (PCA3, AMACR, TRPM8 and MSMB with KLK3 normalization). In this study, we aimed to validate it in a larger cohort with serum PSA $2.5-10 \mathrm{ng} / \mathrm{mL}$ and test other selected transcripts and clinical parameters, including the percentage of free prostate-specific antigen (PSA) (\% free PSA) and inflammation. In the main cohort of 299 men, we tested the quadruplex transcripts. In a subset of 146 men, we analyzed additional transcripts (CD45, EPCAM, EZH2, Ki67, PA2G4, PSGR, RHOA and TBP). After a prostate massage, the urine was collected, RNA isolated from a cell sediment and qRT-PCR performed. Ct values of KLK3 (i.e., PSA) were strongly correlated with Ct values of other genes which play a role in CaP (i.e., PCA3, AMACR, TRPM8, MSMB and PSGR). $A M A C R, P C A 3, T R P M 8$ and EZH2 mRNA expression, as well as \% free PSA, were significantly different for $\mathrm{BPH}$ and CaP. The best combined model (\% free PSA plus PCA3 and AMACR) achieved an AUC of 0.728 in the main cohort. In the subset of patients, the best AUC 0.753 was achieved for the combination of PCA3, \% free PSA, EPCAM and PSGR. PCA3 mRNA was increased in patients with inflammation, however, this did not affect the stratification of patients indicated for prostate biopsy. In conclusion, the percentage of free PSA and urinary markers contribute to a more accurate indication for prostate biopsy.
\end{abstract}

Keywords: prostate cancer; \% free PSA; PCA3; $A M A C R$; inflammation

\section{Introduction}

The definitive diagnosis of prostate cancer $(\mathrm{CaP})$ is based on the results of a prostate biopsy. Due to the complications associated with prostate biopsy, including hospitalization, bleeding, sepsis and pain, it is important to reduce the number of unnecessary biopsies done. For almost 30 years, the decision to biopsy a patient has relied on elevated prostate-specific antigen (PSA) levels or abnormal findings on a digital rectal exam (DRE). Serum PSA is also included in seven well-known multivariable risk calculators which may be used both by patients and clinicians [1]. Besides serum markers, urinary biomarkers may also help urologists to make decisions concerning diagnosis and prognosis. Both 
serum and urine markers have been recently thoroughly reviewed [2-4]. In addition to urine tests and the blood Prostate Health Index or $4 \mathrm{KS}$ core, magnetic resonance imaging (MRI) is also an important option [5-10]. Novel approaches are being tested too, e.g., DNA methylation assays, miRNAs and lncRNAs [11-13].

Based on a preliminary analysis of a subset of patients, we have reported that prostatic inflammation may affect urine PCA3 mRNA levels [14]. There is only one study which analyzed a subgroup of patients with serum PSA 4-10 ng/mL [15], however, the group of BPH (benign prostate hyperplasia) without inflammation was rather small. On the other hand, a well-defined case study supports a potential upregulation of PCA3 score due to inflammation [16].

Most commonly used, the Progensa urine assay has been approved by FDA and KLK3 (i.e., PSA) mRNA levels are important for calculation of the PCA3 score (PCA3 mRNA/PSA mRNA $\times 1000)$. Similar normalization to the prostate specific KLK3 levels is also used in PCR-based assays which enable analysis of additional transcripts of interest. Slightly elevated KLK3 mRNA levels had been reported in urine samples from patients with $\mathrm{CaP}$ [17] and therefore we also assayed TBP (TATA-binding protein) and RHOA (Ras homolog gene family member A) as potential alternative house-keeping genes in the current study. Previously, we have successfully analyzed PCA3 in combination with AMACR (a-methylacyl-CoA racemase), EZH2 (enhancer of zeste homolog 2), MSMB (microseminoprotein, $\beta$ ) and TRPM8 (transient receptor potential cation channel, subfamily M member 8) [18]. In the current study, we were interested if additional markers can improve the stratification of BPH and CaP patients. EPCAM (epithelial cell adhesion molecule) is frequently used as a marker of circulating tumor cells $[19,20]$ but it has not been evaluated in patients' urine yet. There are also no urine-based studies for Ki67 (MKI67, marker of proliferation Ki67). Two studies have reported promising results for cancer detection using PSGR (prostate-specific G-protein coupled receptor, official gene name OR51E2, olfactory receptor 51E2) $[17,21]$. We have also included PA2G4 which acts as an androgen receptor corepressor and may be downregulated in prostate cancer [22]. Last but not least, we were interested if prostate inflammation is reflected by a higher incidence of leukocytes and their specific marker CD45 in the urine.

In this study, we aimed to validate and improve our established quadruplex urine test ([18]; AMACR, PCA3, MSMB, TRPM8, EZH2 with KLK3 normalization) in a cohort of patients with serum PSA 2.5-10 ng/mL. The percentage of free PSA in serum, inflammation in benign prostate tissue and panel of candidate urine transcripts were also evaluated.

\section{Material and Methods}

\subsection{Patients, Inflammation, Urine Collection and RNA Isolation}

The patient clinical and pathological characteristics are shown in Table 1 and Figure $1 \mathrm{~A}$. The study was approved by the Ethics Committee of the University Hospital Olomouc and Medical Faculty of Palacky University in June 2014 (Ref No. 127/14). Verbal informed consent was obtained from all individual participants for the measurement of urine markers as a part of their standard urological examination and for the anonymous data analysis in this study. Written informed consent would have been redundant as the routine clinical procedure was not affected by the noninvasive measurement of urine markers at all. Patients with BPH were divided into two subgroups, those with and those without extensive inflammation according to the histopathological examination by an experienced pathologist $(\mathrm{ZK})$. Urine $(30 \mathrm{~mL})$ was collected after a massage of the prostate during the digital rectal examination and processed within $1 \mathrm{~h}$ from the collection. The urine samples were centrifuged at $650 \times g\left(5 \mathrm{~min}\right.$ at $\left.4{ }^{\circ} \mathrm{C}\right)$ and the cell sediment was used for total RNA isolation by SurePrep Urine Exfoliated Cell RNA Purification Kit (Fisher Scientific). The concentration of RNA was measured on Nanodrop. RNA samples were stored at $-80{ }^{\circ} \mathrm{C}$. 
Table 1. Patients characteristics.

\begin{tabular}{|c|c|c|c|c|}
\hline \multirow{2}{*}{ Characteristics } & \multicolumn{2}{|c|}{ Whole Cohort $(n=299)$} & \multicolumn{2}{|c|}{ Subset $(n=146)$} \\
\hline & ВPH & $\mathrm{CaP}$ & ВРH & $\mathrm{CaP}$ \\
\hline No. Patients & 178 & 121 & 78 & 68 \\
\hline \multicolumn{5}{|l|}{ Age ${ }^{1}$} \\
\hline$<55$ & 17 & 18 & 7 & 7 \\
\hline $55-65$ & 80 & 46 & 31 & 26 \\
\hline$>65$ & 81 & 57 & 40 & 35 \\
\hline \multicolumn{5}{|c|}{ Serum PSA (ng/mL) } \\
\hline$<2.5$ & - & 10 & - & 6 \\
\hline $2.5-10$ & 147 & 111 & 63 & 62 \\
\hline$>10$ & 31 & - & 15 & - \\
\hline \multicolumn{5}{|l|}{$\%$ free PSA ${ }^{2}$} \\
\hline 0-10 & 18 & 12 & 11 & 9 \\
\hline $11-20$ & 49 & 16 & 20 & 12 \\
\hline $21-100$ & 48 & 8 & 24 & 5 \\
\hline \multicolumn{5}{|l|}{ Inflammation ${ }^{3}$} \\
\hline yes & 62 & - & 34 & - \\
\hline no & 83 & - & 43 & - \\
\hline n.a. & 33 & - & 1 & - \\
\hline \multicolumn{5}{|l|}{ Gleason score } \\
\hline$<7$ & - & 39 & - & 18 \\
\hline 7 & - & 70 & - & 41 \\
\hline$>7$ & - & 12 & - & 9 \\
\hline \multicolumn{5}{|l|}{ Cancer stages 4} \\
\hline T1-pT2b & - & 38 & - & 18 \\
\hline pT2c & - & 64 & - & 39 \\
\hline pT3a-b & - & 19 & - & 11 \\
\hline \multicolumn{5}{|l|}{ Risk groups 5} \\
\hline low & - & 26 & - & 10 \\
\hline intermediate & - & 70 & - & 42 \\
\hline high & - & 25 & - & 16 \\
\hline
\end{tabular}

1 There is no difference in age between $\mathrm{BPH}$ and $\mathrm{CaP}$ in any cohort ( $p$ values 0.89 and 0.93 , respectively).

${ }^{2}$ Measurement of $\%$ free PSA was not available for all patients. ${ }^{3}$ Inflammation was considered in BPH tissue only. ${ }^{4}$ No patient was diagnosed with lymph node or distant metastases. ${ }^{5}$ Risk groups were defined as low (T1-pT2b and Gleason score $<7$ ), intermediate (pT2c or Gleason score 7) and high (pT3 or Gleason score > 7). No patients with a particular parameter are indicated by "-".

\subsection{Reverse Transcription and Quantitative Polymerase Chain Reaction}

Total RNA (100 ng) was treated with DNase I (Invitrogen) and then transcribed to cDNA with SuperScript III Reverse Transcriptase (Invitrogen). The quantitative real time polymerase chain reaction (qRT-PCR) was performed with LightCycler 480 Probes Master Mix (Roche) and appropriate primers (Table S1) for 50 cycles of denaturation, annealing and extension $\left(95-60-72{ }^{\circ} \mathrm{C}\right.$ each for $20 \mathrm{~s}$ ) on LightCycler 480 instrument (Roche). All samples were analyzed in duplicate. Samples with KLK3 Ct values $>35$ ( $\mathrm{Ct}$, cycle threshold) and missing values for two or more urine markers were excluded due to a low amount of cDNA. Relative quantification was carried out according to the delta $\mathrm{Ct}(\mathrm{dCt})$ method using a reference gene $\left(\mathrm{dCt}=\mathrm{Ct}_{\text {target }}-\mathrm{Ct}_{K L K 3}\right)$ and inverse values $(-\mathrm{dCt})$ were used for subsequent statistical analysis and visualization.

\subsection{Dilution of LNCaP Cells and Leukocytes}

Prostate cancer cells (LNCaP) were harvested from a standard cell culture and counted in a hemocytometer. Leukocytes were obtained from $5 \mathrm{~mL}$ of EDTA-stabilized blood from a healthy volunteer. After centrifugation at $2300 \times g$, buffy coat was aspirated and lysis of residual erythrocytes was performed with PBS and ddH2O and centrifuged for $5 \mathrm{~min}$ at $300 \mathrm{~g}$. Leukocytes were counted in a 
hemocytometer. Dilution of prostate cancer LNCaP cells and leukocytes was performed according to Figure S2B,C and processed as standard urine samples.

\subsection{Statistical Analysis}

The data were analyzed with respect to the clinical-pathological parameters (percentage of free PSA, inflammation in benign tissue, Gleason score and tumor stage) using the program Statistica 12 (TIBCO Software Inc., Palo Alto, CA, USA, Mann-Whitney test, Spearman's rank correlation coefficient and Pearson's chi-squared test). Graphs were generated in GraphPad Prism 8 (GraphPad Software, San Diego, CA, USA). Univariate and multivariate logistic regression analyses were performed with software R, ver. 3.5.0 (www.r-project.org). The best multivariate model was always chosen from a group of models generated in best subset selection process (using the bess function from BeSS $\mathrm{R}$ package, ver. 1.0.5) as a model with the smallest testing error rate estimated by LOOCV. ROC curves were generated with function ROC from package Epi, ver. 2.30, while AUCs (areas under the ROC curve) altogether with 95\% confidence intervals (computed with 2000 stratified bootstrap replicates) were calculated with functions from pROC package, ver. 1.12.1. The $p$-values which address the null hypothesis that the AUC is 0.5 were calculated using the Wilcox test function using the roc.area function from verification package, ver. 1.42 .

A

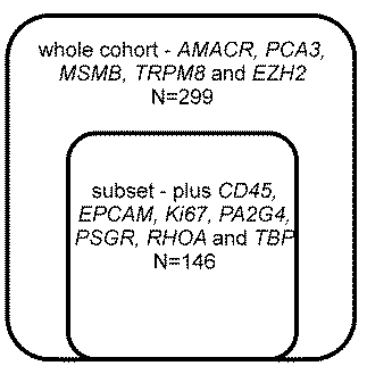

D

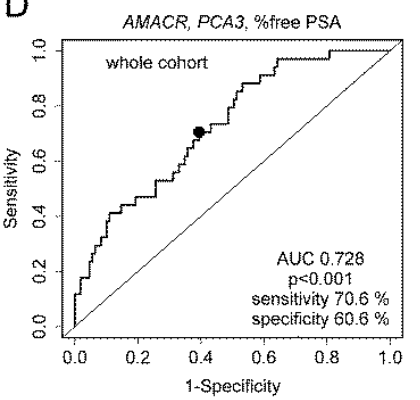

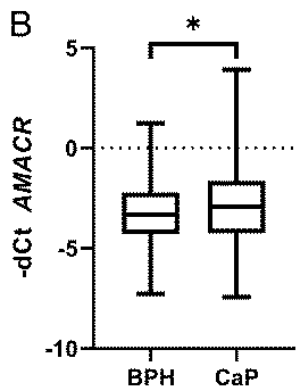

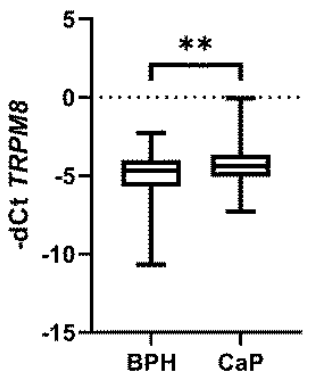

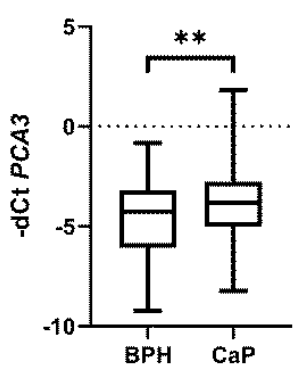

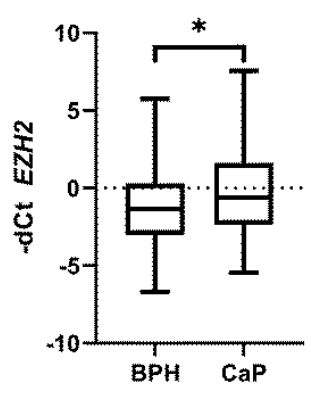

C

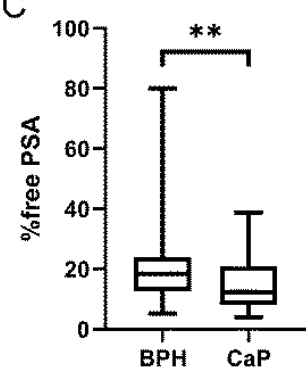

$\mathrm{E}$

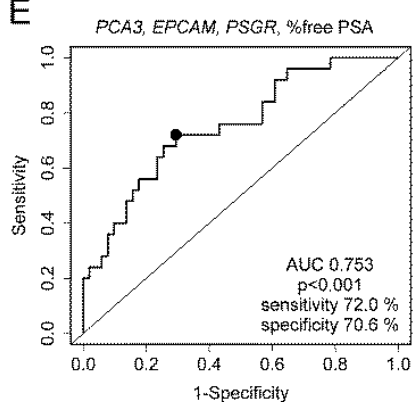

Figure 1. Urine markers are differentially expressed between CaP and BPH. (A) Description of the whole cohort and a subset of patients analyzed for indicated transcripts. (B) AMACR, PCA3, TRPM8 and $E Z H 2$ expression were significantly different for $\mathrm{CaP}$ and $\mathrm{BPH}$ patients ( $p$ values $0.045,0.004,0.005$ and 0.019 , respectively). (C) Percentage of free PSA in combination with urine markers contribute to discrimination of $\mathrm{BPH}$ from $\mathrm{CaP}$. Percentage of free PSA significantly discriminates $\mathrm{CaP}$ from $\mathrm{BPH}$ ( $p$ value 0.003 ). Box-plots represent median, $25-75 \%$ percentiles and range of values. $p$-values $<0.05$ and $<0.01$ are indicated by * and ${ }^{* *}$, respectively. (D) Receiver-operating characteristic analysis for $\%$ free PSA in combination with urinary markers $A M A C R$ and PCA3 or (E) with EPCAM, PCA3 and PSGR in the subset of patients. 


\section{Results}

\subsection{Urine KLK3 Strongly Correlates with Prostate Cancer Relevant Transcripts}

The patients clinical and pathological characteristics are shown in Table 1. Our expression analysis of 13 urine transcripts enabled a unique analysis using a non-parametric Spearman's rank correlation coefficient (Table 2). As expected, KLK3 Ct values strongly correlated with $\mathrm{Ct}$ values of other genes which have been reported to play a role in prostate cancer (i.e., PCA3, AMACR, TRPM8, MSMB and PSGR). A weaker correlation was observed for EPCAM which suggests the presence of other epithelial cells from the urinary tract. CD45 expression strongly correlated with EZH2 and in particular with house-keeping genes TBP and RHOA, indicating the abundant presence of leukocytes in urine.

As elevated KLK3 mRNA levels had been reported in urine samples from patients with CaP [17], we also assayed other house-keeping genes. However, none of the genes used for alternate normalization (TBP, RHOA, PA2G4, EPCAM) outperformed KLK3. In fact, there was only a trend for decreased KLK3 in CaP compared to BPH when normalized to EPCAM $(p=0.083)$ and a trend for increased PCA3 in $\mathrm{CaP}$ when normalized to PA2G4 ( $p=0.095)$ in the relevant subset of patients (Figure $1 \mathrm{~A})$. Therefore standard normalization to KLK3 Ct values was used for all urine markers below.

\subsection{Urine PCA3, AMACR and Percentage of Free PSA Discriminate CaP from BPH}

The major aim of this study was validation of our previous results $(A M A C R, P C A 3, M S M B$, TRPM8, EZH2 with KLK3 normalization) in an extended cohort of patients with total PSA levels 2.5-10 ng/mL (Table 1). A subset of patients $(n=146)$ was also evaluated for additional transcripts (CD45, EPCAM, Ki67, PA2G4, PSGR, RHOA, TBP, Figure 1A, please see below Section 2.3). In the whole cohort benign cases with PSA levels above $10 \mathrm{ng} / \mathrm{mL}(n=31)$ and cancer cases below $2.5 \mathrm{ng} / \mathrm{mL}$ $(n=10)$ were also included (Table 1$)$. Significantly different expressions between BPH and CaP were found for AMACR ( $p=0.045)$, PCA3 $(p=0.004)$, TRPM8 $(p=0.005)$ and EZH2 $(p=0.019$, Figure 1B). As expected, $\%$ of free PSA was also significantly different for BPH and CaP cases ( $p$ value 0.003 , Figure 1C). Importantly, the percentage of free PSA alone had an AUC 0.66 (Table 3). Multivariate logistic analysis of all parameters identified the best combined model (\% free PSA plus PCA3 and AMACR) with improved AUC 0.728 (Table 3, Figure 1D).

\subsection{The Best Combined Model was Achieved for EPCAM, PSGR, PCA3 and Percentage of Free PSA in the Subset of Patients}

We were also interested if novel markers (EPCAM, PSGR, Ki67, PA2G4) can improve stratification of $\mathrm{BPH}$ and $\mathrm{CaP}$ in a subset of patients $(n=146$, Figure $1 \mathrm{~A})$. Other aims were to evaluate the normalization of gene expression (KLK3, RHOA and TBP; please see above Section 2.1) and to analyze the presence of leukocytes in the urine ( $C D 45$; please see Section 2.4 below). Although none of the novel transcripts were different between $\mathrm{BPH}$ and $\mathrm{CaP}$, the multivariable analysis revealed an alternative combination of EPCAM, PSGR, PCA3 and \% free PSA with AUC 0.753 (Table 3, Figure 1E). However, this promising model needs to be validated on a larger cohort of patients. 
Table 2. Spearman's correlations between Ct values with emphasis on KLK3 and CD45.

\begin{tabular}{|c|c|c|c|c|c|c|c|c|c|c|c|c|c|}
\hline & KLK3 & $A M A C R$ & PCA3 & TRPM8 & $M S M B$ & $E Z H 2$ & CD45 & EPCAM & Ki67 & RHOA & PA2G4 & PSGR & TBP \\
\hline KLK3 & 1.000 & 0.720 & 0.791 & 0.863 & 0.895 & 0.292 & -0.092 & 0.489 & 0.154 & 0.192 & 0.433 & 0.826 & 0.169 \\
\hline$A M A C R$ & & 1.000 & 0.685 & 0.663 & 0.680 & 0.562 & 0.186 & 0.507 & 0.350 & 0.463 & 0.665 & 0.647 & 0.431 \\
\hline PCA3 & & & 1.000 & 0.770 & 0.682 & 0.274 & -0.027 & 0.426 & 0.191 & 0.240 & 0.411 & 0.747 & 0.225 \\
\hline TRPM8 & & & & 1.000 & 0.827 & 0.317 & 0.007 & 0.582 & 0.256 & 0.324 & 0.506 & 0.746 & 0.318 \\
\hline$M S M B$ & & & & & 1.000 & 0.403 & 0.050 & 0.462 & 0.184 & 0.266 & 0.474 & 0.711 & 0.215 \\
\hline$E Z H 2$ & & & & & & 1.000 & 0.775 & 0.259 & 0.530 & 0.738 & 0.669 & 0.039 & 0.685 \\
\hline$C D 45$ & & & & & & & 1.000 & 0.157 & 0.491 & 0.809 & 0.588 & -0.126 & 0.718 \\
\hline EPCAM & & & & & & & & 1.000 & 0.500 & 0.425 & 0.496 & 0.368 & 0.457 \\
\hline Ki67 & & & & & & & & & 1.000 & 0.586 & 0.624 & 0.075 & 0.626 \\
\hline RHOA & & & & & & & & & & 1.000 & 0.819 & 0.105 & 0.926 \\
\hline PA2G4 & & & & & & & & & & & 1.000 & 0.384 & 0.827 \\
\hline PSGR & & & & & & & & & & & & 1.000 & 0.126 \\
\hline TBP & & & & & & & & & & & & & 1.000 \\
\hline
\end{tabular}

Strong correlations (Rs $>0.7)$ are highlighted in bold. Insignificant results $(p>0.001)$ are in italics. 
Table 3. Univariate and multivariate analysis.

\begin{tabular}{|c|c|c|c|c|c|}
\hline \multicolumn{4}{|c|}{ Univariate Logistic Analysis } & \multicolumn{2}{|c|}{ ROC Analysis } \\
\hline Variable & $\beta$ & OR $(95 \% \mathrm{CI})$ & $p$-Value & AUC (95\% CI) & $p$-Value \\
\hline$A M A C R$ & 0.168 & $1.183(1.031-1.357)$ & 0.017 & $0.569(0.502-0.635)$ & 0.023 \\
\hline PCA3 & 0.233 & $1.263(1.09-1.463)$ & 0.002 & $0.602(0.533-0.667)$ & 0.002 \\
\hline TRPM8 & 0.341 & $1.406(1.143-1.73)$ & 0.001 & $0.599(0.532-0.664)$ & 0.003 \\
\hline$M S M B$ & 0.07 & $1.072(0.883-1.303)$ & 0.482 & $0.526(0.458-0.594)$ & 0.223 \\
\hline$E Z H 2$ & 0.127 & $1.136(1.037-1.244)$ & 0.006 & $0.587(0.519-0.653)$ & 0.007 \\
\hline EPCAM & 0.141 & $1.152(0.991-1.338)$ & 0.065 & $0.585(0.488-0.674)$ & 0.042 \\
\hline PSGR & 0.127 & $1.135(0.888-1.451)$ & 0.311 & $0.532(0.44-0.633)$ & 0.255 \\
\hline$\%$ free PSA & -0.075 & $0.928(0.879-0.98)$ & 0.007 & $0.666(0.559-0.763)$ & 0.001 \\
\hline \multicolumn{4}{|c|}{ Multivariate Logistic Analysis } & \multicolumn{2}{|c|}{ ROC Analysis } \\
\hline Whole Cohort & $\beta$ & OR $(95 \%$ CI $)$ & $p$-Value & AUC (95\% CI) & $p$-Value \\
\hline age & 0.043 & $1.044(0.97-1.123)$ & 0.256 & $0.728(0.633-0.816)$ & $<0.001$ \\
\hline$A M A C R$ & 0.244 & $1.277(0.943-1.729)$ & 0.114 & & \\
\hline PCA3 & 0.283 & 1.327 (1.01-1.742) & 0.042 & & \\
\hline$\%$ free PSA & -0.082 & $0.921(0.871-0.975)$ & 0.004 & & \\
\hline Subset & $\beta$ & OR $(95 \% \mathrm{CI})$ & $p$-Value & AUC (95\% CI) & $p$-Value \\
\hline PCA3 & 0.439 & $1.551(1.092-2.205)$ & 0.014 & $0.753(0.642-0.862)$ & $<0.001$ \\
\hline EPCAM & 0.207 & $1.23(0.935-1.619)$ & 0.139 & & \\
\hline PSGR & -0.151 & $0.86(0.578-1.278)$ & 0.454 & & \\
\hline$\%$ free PSA & -0.064 & $0.938(0.877-1.004)$ & 0.064 & & \\
\hline
\end{tabular}

AUC, area under curve; OR, odds ratio; ROC, receiver-operating characteristic; $\beta$, beta coefficient; $95 \%$ CI, $95 \%$ confidence interval.

\subsection{Prostate Inflammation in BPH Increases Urine PCA3 but Does Not Affect Prostate Biopsy Decision Making}

One of the first studies on $P C A 3$ by Hessels et al. provided data on inflammation in 84 patients with no malignancy [23]. There was no association of inflammation with $P C A 3$, and surprisingly, also not with serum PSA (Figure S1). In our previous study [24], we histopathologically evaluated inflammation in needle biopsies of BPH. Based on a preliminary analysis, we reported that prostatic inflammation may affect urine PCA3 [13]. This observation was confirmed in the present study where both PCA3 $(p=0.041)$ and serum PSA $(p=0.005)$ were significantly increased in patients with inflammation (Figure 2). Importantly, the slight increase of $P C A 3$ did not significantly alter stratification of BPH cases with and without inflammation into risk groups based on the combined evaluation of $P C A 3, A M A C R$ and $\%$ free PSA $(p=0.89)$.
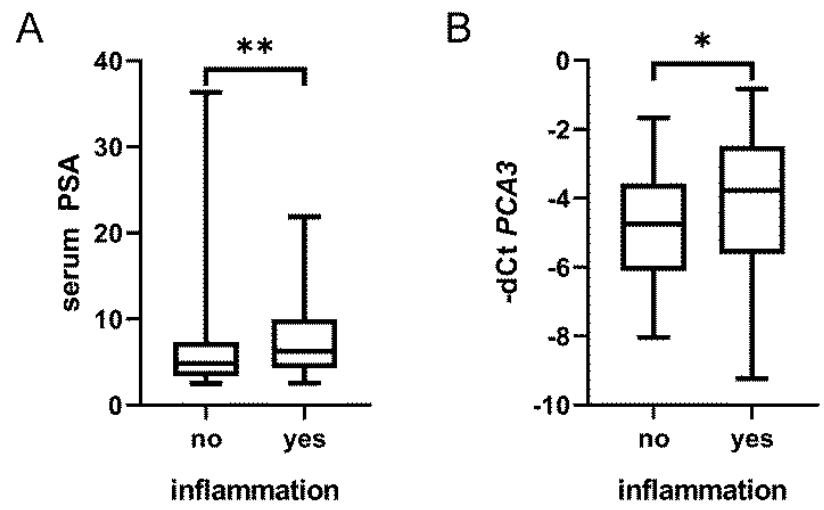

Figure 2. Inflammation in BPH tissue affects serum PSA and urine PCA3. Serum PSA levels (A) and to a lesser extent also urine PCA3 (B) were significantly higher in patients with inflamed BPH tissue ( $p$ values 0.005 and 0.040 , respectively). Box-plots represent median, 25-75\% percentiles and range of values. $p$-values $<0.05$ and $<0.01$ are indicated by ${ }^{*}$ and ${ }^{* *}$, respectively. 


\subsection{The qRT-PCR Assay Detects Relevant Numbers of Leukocytes and Cancer Cells in Urine}

As mentioned above, CD45 mRNA was abundant in urine samples (Table 2, Figure S2A), but the levels were no different in benign patients with and without inflammation $(p=0.17)$. We were interested if our qRT-PCR assay detects relevant numbers of leukocytes (CD45 positive) and cancer cells (KLK3 positive) in urine and performed a simple dilution experiment (see Methods 4.3). As reported by others, $30 \mathrm{~mL}$ of urine may contain 100,000 leukocytes which may further increase during urinary tract inflammation [25-27]. This number of leukocytes from a volunteer provided a Ct value of CD45 close to 30 (Figure S2B) which was very similar to the mean of our urine samples (CD45 mean 29.6). The mean Ct value for KLK3 from patient samples was 31.2 which was close to the value of $1000 \mathrm{LNCaP}$ prostate cancer cells (Figure S2C). These results are in good concordance with an image-based analysis which consistently detected $1000 \mathrm{LNCaP}$ cells spiked in urine [19]. Tens to several thousands of cancer cells were detected in urine samples from 35 patients [19] which is well mirrored in the variability of Ct values from our patients' samples (Figure S2A).

\section{Discussion}

Our study supports a combined analysis of urine and blood tests for the more accurate indication for prostate biopsy. Best results were achieved with a combination of $A M A C R, P C A 3$ and \% free PSA. A separate analysis of $P C A 3$ and $\%$ free PSA has previously been reported $[28,29]$. For example, Ploussard et al. found PCA3 score superior to \% free PSA in patients with "grey zone" PSA values (2.5-10 ng/mL) [28]. Auprich et al. examined patients at first, second, and $\geq$ third repeat biopsy sessions [29]. At first repeat biopsy, PCA3 predicted CaP best while $\%$ free PSA performed best at second and $\geq$ third repeat biopsies. Clinicians and patients have many other options for refinement of prostate biopsy decision making, depending on available methods and funding. Besides the urine Select MDx, ExoDx and TMPRSS2-ERG [30-35] and the blood Prostate Health Index and 4KScore [5-8], MRI is also an important option [9]. Combination of multiparametric MRI (mp-MRI) with urinary $P C A 3$ or Select MDx has recently shown a potential to reduce unnecessary biopsies, which could, in turn, prevent overdiagnosis and overtreatment [10,32]. Multiparametric MRI has recently been established in our hospital and we also aim to implement it in the prospective validation of our models. In particular, the value of EPCAM and PSGR urinary transcripts deserves further analysis as they have so far been reported only in few studies $[17,21,36]$.

The validity of our method was reflected in the strong correlation of prostate related genes, i.e., KLK3, PCA3, AMACR, TRPM8, MSMB and PSGR. A weaker correlation was observed for $E P C A M$ which suggests the presence of other epithelial cells from the urinary tract. Still, combined evaluation of EPCAM, PSGR, PCA3 and percentage of free PSA showed promising results in the discrimination of $\mathrm{CaP}$ and $\mathrm{BPH}$ patients. We have not proved the importance of PA2G4 and Ki67 for $\mathrm{CaP}$ detection as they weakly correlated with some prostate cancer-related markers (e.g., $A M A C R$ ), but also with leukocyte-specific $C D 45$ and house-keeping genes (TBP and RHOA). CD45 expression strongly correlated with $E Z H 2$ and in particular with house-keeping genes $T B P$ and $R H O A$, indicating the abundant presence of leukocytes in urine.

CD45 mRNA was abundant in urine samples but the levels were no different in benign patients with and without inflammation. However, we only had information on inflammation from the prostate tissue which is probably a minor source of leukocytes in the urine. Based on a preliminary analysis, we have previously reported that prostatic inflammation may affect urine PCA3 [14]. This observation was confirmed in the current study where both PCA3 $(p=0.041)$ and serum PSA $(p=0.005)$ were increased in patients with inflammation. This is in line with a case report where symptomatic male urethral Chlamydia trachomatis infection resulted in inflammation of the prostate, with associated increases in both PSA and PCA3 [16]. Although several articles have reported no association between $P C A 3$ and inflammation, most of these included patients with any serum PSA level. One of the first studies analyzed $P C A 3$ in 84 patients with no malignancy and with no limit on serum PSA levels [23]. From the data provided, there was no association of inflammation with $P C A 3$, but surprisingly, also not 
with serum PSA. No association between PCA3 and inflammation was also reported in other cohorts with no limit on serum PSA [37-39]. The third study [39] consisted of young patients and provided no information on serum PSA, which was also commented on elsewhere [40]. The last study on PCA3 and inflammation analyzed a subgroup of patients with serum PSA levels $4-10 \mathrm{ng} / \mathrm{mL}$ [15]. PCA3 was no different for patients with prostatitis and patients with $\mathrm{BPH}$. However, the group with $\mathrm{BPH}$ without inflammation was rather small (30 patients with any serum PSA level and the exact number of the patients with "grey zone" PSA values was not specified). Although we found a slight increase of PCA3 in patients with inflammation, this did not affect the stratification of patients indicated for prostate biopsy. Last but not least, prostate inflammation and its evaluation in urine will deserve further research by different methods, such as urine test strips, image-based analysis or mass spectrometry.

In summary, our study supports a combined analysis of urine and blood tests for the more accurate indication for prostate biopsy. Best results were achieved with a combination of AMACR, PCA3 and \% free PSA. PCA3 was slightly increased by tissue inflammation but without effect on the interpretation of the urine test.

Supplementary Materials: The following are available online at http://www.mdpi.com/2227-9059/8/6/173/s1.

Author Contributions: Measured levels of urine transcripts and drafted the manuscript, Z.H.; measured levels of urine transcripts, J.K.; assessed inflammation in the benign prostate tissue, Z.K.; performed the statistical analysis, J.V.; contributed to the collection of samples and all clinical data, M.K.; conceived the study and drafted the manuscript, J.B. All authors have read and agreed to the published version of the manuscript.

Funding: This work was supported by grants 15-28628A and DRO (FNOl, 00098892) from the Czech Ministry of Health. Allocated funding was only used for the purchase of reagents and part time employment. The funding body did not play any role in the design of the study, collection, analysis and interpretation of data, or in writing the manuscript.

Acknowledgments: We sincerely thank Jana Holinkova for her excellent technical assistance.

Conflicts of Interest: The authors have no conflict of interest to declare.

\section{References}

1. Pereira-Azevedo, N.; Verbeek, J.F.M.; Nieboer, D.; Bangma, C.H.; Roobol, M.J. Head-to-head comparison of prostate cancer risk calculators predicting biopsy outcome. Transl. Androl. Urol. 2018, 7, 18-26. [CrossRef] [PubMed]

2. Raja, N.; Russell, C.M.; George, A.K. Urinary markers aiding in the detection and risk stratification of prostate cancer. Transl. Androl. Urol. 2018, 7, 436-442. [CrossRef] [PubMed]

3. Cucchiara, V.; Cooperberg, M.R.; Dall'Era, M.; Lin, D.W.; Montorsi, F.; Schalken, J.A.; Evans, C.P. Genomic Markers in Prostate Cancer Decision Making. Eur. Urol. 2018, 73, 572-582. [CrossRef]

4. Kearns, J.T.; Lin, D.W. Improving the Specificity of PSA Screening with Serum and Urine Markers. Curr. Urol. Rep. 2018, 19, 80. [CrossRef] [PubMed]

5. Stephan, C.; Ralla, B.; Jung, K. Prostate-specific antigen and other serum and urine markers in prostate cancer. Biochim. Biophys. Acta Rev. Cancer 2014, 1846, 99-112. [CrossRef] [PubMed]

6. Nicholson, A.; Mahon, J.; Boland, A.; Beale, S.; Dwan, K.; Fleeman, N.; Hockenhull, J.; Dundar, Y. The clinical effectiveness and cost-effectiveness of the PROGENSA(R) prostate cancer antigen 3 assay and the Prostate Health Index in the diagnosis of prostate cancer: A systematic review and economic evaluation. Health Technol. Assess. 2015, 19, 1-192. [CrossRef] [PubMed]

7. Parekh, D.J.; Punnen, S.; Sjoberg, D.D.; Asroff, S.W.; Bailen, J.L.; Cochran, J.S.; Concepcion, R.; David, R.D.; Deck, K.B.; Dumbadze, I.; et al. A multi-institutional prospective trial in the USA confirms that the 4Kscore accurately identifies men with high-grade prostate cancer. Eur. Urol. 2015, 68, 464-470. [CrossRef]

8. Vickers, A.J.; Eastham, J.A.; Scardino, P.T.; Lilja, H. The Memorial Sloan Kettering Cancer Center Recommendations for Prostate Cancer Screening. Urology 2016, 91, 12-18. [CrossRef]

9. Ahmed, H.U.; El-Shater Bosaily, A.; Brown, L.C.; Gabe, R.; Kaplan, R.; Parmar, M.K.; Collaco-Moraes, Y.; Ward, K.; Hindley, R.G.; Freeman, A.; et al. Diagnostic accuracy of multi-parametric MRI and TRUS biopsy in prostate cancer (PROMIS): A paired validating confirmatory study. Lancet 2017, 389, 815-822. [CrossRef] 
10. Perlis, N.; Al-Kasab, T.; Ahmad, A.; Goldberg, E.; Fadak, K.; Sayyid, R.; Finelli, A.; Kulkarni, G.; Hamilton, R.; Zlotta, A.; et al. Defining a Cohort that May Not Require Repeat Prostate Biopsy Based on PCA3 Score and Magnetic Resonance Imaging: The Dual Negative Effect. J. Urol. 2018, 199, 1182-1187. [CrossRef]

11. Smith, B.; Agarwal, P.; Bhowmick, N.A. MicroRNA applications for prostate, ovarian and breast cancer in the era of precision medicine. Endocr. Relat. Cancer 2017, 24, R157-R172. [CrossRef] [PubMed]

12. Helsmoortel, H.; Everaert, C.; Lumen, N.; Ost, P.; Vandesompele, J. Detecting long non-coding RNA biomarkers in prostate cancer liquid biopsies: Hype or hope? Non-Coding RNA Res. 2018, 3, 64-74. [CrossRef]

13. Larsen, L.K.; Jakobsen, J.S.; Abdul-Al, A.; Guldberg, P. Noninvasive Detection of High Grade Prostate Cancer by DNA Methylation Analysis of Urine Cells Captured by Microfiltration. J. Urol. 2018, 200, 749-757. [CrossRef] [PubMed]

14. Kral, M.; Grepl, M.; Hruska, F.; Hradil, D.; Rajmon, P.; Student, V.; Knillova, J.; Bouchal, J. Effect of prostatic tissue inflammation on prostate cancer markers in urine. Eur. Urol. Suppl. 2015, 14, e1285. [CrossRef]

15. De Luca, S.; Passera, R.; Fiori, C.; Bollito, E.; Cappia, S.; Mario Scarpa, R.; Sottile, A.; Rondone, D.F.; Porpiglia, F. Prostate health index and prostate cancer gene 3 score but not percent-free Prostate Specific Antigen have a predictive role in differentiating histological prostatitis from PCa and other nonneoplastic lesions (BPH and HG-PIN) at repeat biopsy. Urol. Oncol. 2015, 33, 424.e17-424.e23. [CrossRef] [PubMed]

16. Smelov, V.; Novikov, A.; Brown, L.J.; Eklund, C.; Strokova, L.; Ouburg, S.; Morre, S.A.; Dillner, J. False-positive prostate cancer markers in a man with symptomatic urethral Chlamydia trachomatis infection. Int. J. STD AIDS 2013, 24, 501-502. [CrossRef]

17. Sequeiros, T.; Bastaros, J.M.; Sanchez, M.; Rigau, M.; Montes, M.; Placer, J.; Planas, J.; de Torres, I.; Pegtel, D.M.; Doll, A.; et al. Urinary biomarkers for the detection of prostate cancer in patients with high-grade prostatic intraepithelial neoplasia. Prostate 2015, 75, 1102-1113. [CrossRef]

18. Jamaspishvili, T.; Kral, M.; Khomeriki, I.; Vyhnankova, V.; Mgebrishvili, G.; Student, V.; Kolar, Z.; Bouchal, J. Quadriplex model enhances urine-based detection of prostate cancer. Prostate Cancer Prostatic Dis. 2011, 14, 354-360. [CrossRef]

19. Fujita, K.; Pavlovich, C.P.; Netto, G.J.; Konishi, Y.; Isaacs, W.B.; Ali, S.; De Marzo, A.; Meeker, A.K. Specific detection of prostate cancer cells in urine by multiplex immunofluorescence cytology. Hum. Pathol. 2009, 40, 924-933. [CrossRef]

20. Joosse, S.A.; Gorges, T.M.; Pantel, K. Biology, detection and clinical implications of circulating tumor cells. EMBO Mol. Med. 2015, 7, 1-11. [CrossRef]

21. Cao, C.; Wang, Q.; Li, Q.; Zhao, Q.; Wang, J.Q.; Liu, Y. Development and Preliminary Clinical Application of Circulating Tumor Cell Detection System for Prostate Cancer. J. Biomed. Nanotechnol. 2019, 15, 612-620. [CrossRef]

22. Zhang, Y.; Linn, D.; Liu, Z.; Melamed, J.; Tavora, F.; Young, C.Y. EBP1, an Erb3-Binding protein, is decreased in prostate cancer and implicated in hormone resistance. Mol. Cancer Ther. 2008, 7, 3176-3186. [CrossRef] [PubMed]

23. Hessels, D.; Klein Gunnewiek, J.M.T.; van Oort, I.; Karthaus, H.F.M.; van Leenders, G.J.L.; van Balken, B.; Kiemeney, L.A.; Witjes, J.A.; Schalken, J.A. DD3(PCA3)-based molecular urine analysis for the diagnosis of prostate cancer. Eur. Urol. 2003, 44, 8-16. [CrossRef]

24. Kucerova, R.; Bienova, M.; Kral, M.; Bouchal, J.; Trtkova, K.S.; Burdova, A.; Student, V.; Kolar, Z. Androgenetic alopecia and polymorphism of the androgen receptor gene (SNP rs6152) in patients with benign prostate hyperplasia or prostate cancer. J. Eur. Acad. Dermatol. Venereol. 2015, 29, 91-96. [CrossRef] [PubMed]

25. Wilson, M.L.; Gaido, L. Laboratory diagnosis of urinary tract infections in adult patients. Clin. Infect. Dis. 2004, 38, 1150-1158. [CrossRef] [PubMed]

26. Dos Santos, J.C.; Weber, L.P.; Perez, L.R.R. Evaluation of urinalysis parameters to predict urinary-tract infection. Braz. J. Infect. Dis. 2007, 11, 479-481. [CrossRef] [PubMed]

27. Musher, D.M.; Thorsteinsson, S.B.; Airola, V.M., II. Quantitative urinalysis. Diagnosing urinary tract infection in men. JAMA 1976, 236, 2069-2072. [CrossRef] [PubMed]

28. Ploussard, G.; Haese, A.; van Poppel, H.; Marberger, M.; Stenzl, A.; Mulders, P.F.A.; Huland, H.; Bastien, L.; Abbou, C.-C.; Remzi, M.; et al. The prostate cancer gene 3 (PCA3) urine test in men with previous negative biopsies: Does free-to-total prostate-specific antigen ratio influence the performance of the PCA3 score in predicting positive biopsies? BJU Int. 2010, 106, 1143-1147. [CrossRef] 
29. Auprich, M.; Augustin, H.; Budäus, L.; Kluth, L.; Mannweiler, S.; Shariat, S.F.; Fisch, M.; Graefen, M.; Pummer, K.; Chun, F.K.-H. A comparative performance analysis of total prostate-specifi c antigen, percentage free prostate-specific antigen, prostate-specifi c antigen velocity and urinary prostate cancer gene 3 in the fi rst, second and third repeat prostate biopsy. BJU Int. 2012, 109, 1627-1635. [CrossRef]

30. Leyten, G.H.J.M.; Hessels, D.; Jannink, S.A.; Smit, F.P.; de Jong, H.; Cornel, E.B.; de Reijke, T.M.; Vergunst, H.; Kil, P.; Knipscheer, B.C.; et al. Prospective multicentre evaluation of PCA3 and TMPRSS2-ERG gene fusions as diagnostic and prognostic urinary biomarkers for prostate cancer. Eur. Urol. 2014, 65, 534-542. [CrossRef]

31. Van Neste, L.; Hendriks, R.J.; Dijkstra, S.; Trooskens, G.; Cornel, E.B.; Jannink, S.A.; de Jong, H.; Hessels, D.; Smit, F.P.; Melchers, W.J.G.; et al. Detection of High-grade Prostate Cancer Using a Urinary Molecular Biomarker-Based Risk Score. Eur. Urol. 2016, 70, 740-748. [CrossRef] [PubMed]

32. Hendriks, R.J.; van der Leest, M.M.G.; Dijkstra, S.; Barentsz, J.O.; Van Criekinge, W.; Hulsbergen-van de Kaa, C.A.; Schalken, J.K.; Mulders, P.F.A.; van Oort, I.M. A urinary biomarker-based risk score correlates with multiparametric MRI for prostate cancer detection. Prostate 2017, 77, 1401-1407. [CrossRef]

33. McKiernan, J.; Donovan, M.J.; Margolis, E.; Partin, A.; Carter, B.; Brown, G.; Torkler, P.; Noerholm, M.; Skog, J.; Shore, N.; et al. A Prospective Adaptive Utility Trial to Validate Performance of a Novel Urine Exosome Gene Expression Assay to Predict High-grade Prostate Cancer in Patients with Prostate-specific Antigen 2-10ng/ml at Initial Biopsy. Eur. Urol. 2018, 74, 731-738. [CrossRef] [PubMed]

34. Tomlins, S.A.; Day, J.R.; Lonigro, R.J.; Hovelson, D.H.; Siddiqui, J.; Kunju, L.P.; Dunn, R.L.; Meyer, S.; Hodge, P.; Groskopf, J.; et al. Urine TMPRSS2:ERG Plus PCA3 for Individualized Prostate Cancer Risk Assessment. Eur. Urol. 2016, 70, 45-53. [CrossRef] [PubMed]

35. Sanda, M.G.; Feng, Z.; Howard, D.H.; Tomlins, S.A.; Sokoll, L.J.; Chan, D.W.; Regan, M.M.; Groskopf, J.; Chipman, J.; Patil, D.H.; et al. Association Between Combined TMPRSS2:ERG and PCA3 RNA Urinary Testing and Detection of Aggressive Prostate Cancer. JAMA Oncol. 2017, 3, 1085-1093. [CrossRef] [PubMed]

36. Zhou, Y.; Li, Y.; Li, X.; Jiang, M. Urinary Biomarker Panel to Improvement in Predicting Prostate Biopsy Result in Chinese Men with PSA 4-10 nj/mL. Biomed. Res. Int. 2017, 2017, 1-9.

37. Deras, I.L.; Aubin, S.M.J.; Blase, A.; Day, J.R.; Koo, S.; Partin, A.W.; Ellis, W.J.; Marks, L.S.; Fradet, Y.; Rittenhouse, H.; et al. PCA3: A molecular urine assay for predicting prostate biopsy outcome. J. Urol. 2008, 179, 1587-1592. [CrossRef]

38. De Luca, S.; Passera, R.; Milillo, A.; Coda, R.; Randone, D.F. Histological chronic prostatitis and high-grade prostate intra-epithelial neoplasia do not influence urinary prostate cancer gene 3 score. BJU Int. 2012, 110, 778-782. [CrossRef]

39. Vlaeminck-Guillem, V.; Bandel, M.; Cottancin, M.; Rodriguez-Lafrasse, C.; Bohbot, J.-M.; Sednaoui, P. Chronic prostatitis does not influence urinary PCA3 score. Prostate 2012, 72, 549-554. [CrossRef]

40. Schaeffer, E.M. Re: Chronic prostatitis does not influence urinary PCA3 score. J. Urol. 2012, 188, 2242. [CrossRef]

(C) 2020 by the authors. Licensee MDPI, Basel, Switzerland. This article is an open access article distributed under the terms and conditions of the Creative Commons Attribution (CC BY) license (http://creativecommons.org/licenses/by/4.0/). 